\title{
Appreciation of Stakeholders in Port Maneuver Regarding the Origin of Risk and its Consequences: The Case of Algerian Ports
}

\section{Bouzaher Abdelhakim $^{1 *}$ and Mati Manoubia ${ }^{2}$}

${ }^{1}$ Research Laboratory in the Maritime Transportation Security Setram, Maritim National Superior School, Bou Ismail, Algeria

${ }^{2}$ Research Laboratory in Education, Training Labour/Alger University, Algeria

\begin{abstract}
The present study is a continuation of our first work, which was conducted in Algerian ports, the objective of which was the management of risks related to port maneuver in Algeria. This study aims to achieve a better understanding of stakeholder's perception in the matter of port maneuver regarding the origin of risk and its consequences. This perception may be either objective or subjective. What is important is that this study reflects a reality that can enlighten experts and decision makers, thus allowing them to make specific decisions. Seventy-two stakeholders in maneuver from ten different Algerian ports have responded to our questionnaire on risk perception. The results confirmed that different parameters are at the origin of this perception.
\end{abstract}

Keywords: Risk perception; Port maneuver; Algerian ports

\section{Introduction}

The prevention of risks and accidents is an objective that every work structure aims to achieve. This could be possible according to studies by increasing the reliability of equipment and by taking into account the behavior of operators. The latter can neither be controlled nor planned for without the knowledge of the operator's perception of the risk [1].

\section{Theoretical aspects}

The approach to risk which focuses on the individual variables of the operator, is complementary to that which focuses on the environment and its technical characteristics, activity and organizational system etc. [2].

Several models have been designed to study safety based on the operator's perception. The basic argument of these models is that security measures are generally designed by experts according to their inferences, which are not always the same as those of the operators who are supposed to apply them. Yet, the Judgment of the operator is fundamental in any risk assessment. The risk that has a natural origin according to studies is a social construction [3-5]. A malfunction only appears when it is perceived as such, meaning only when there is a shift in the so-called normal situation. Thus, risks are closely linked to the social perceptions of the people who will refuse or accept to incur risks. This risk, which is built socially, perceived, invented is not necessarily objective.

It will be question in this work to know the perception of risk among stakeholders in a very particular field, which is port maneuver [6-9].

\section{Methodology}

The study is essentially conducted alongside maritime pilots in ten Algerian ports.

\section{Subjects}

We have opted in this study for an approach that was meant to be as exhaustive as possible, which, according to studies, can be fulfilled by including as many subjects as possible [10-13]. Thus, seventy two stakeholders occupying different positions have participated in this study, amongst a population of one hundred and three (103) pilots (Figures 1-4). The subjects are mainly maritime pilots, practicing in all Algerian ports and having varying levels of professional experience

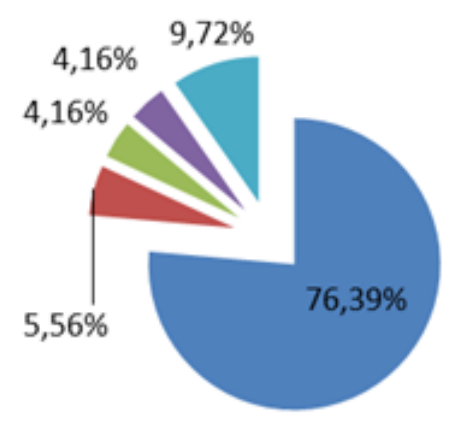

- Pilot

- Harboard Master

- Head of

Department

chief Pilot

without answer

Figure 1: Functions of the stakeholders.

\section{Instruments}

A direct administration questionnaire was conceived for the purposes of this study, composed of ten closed and open questions, and was distributed to stakeholders in port maneuver.

The axes of the questionnaire (see appendix) are a set of variables that can be at the origin of risk in port maneuver according to the perception of stakeholders in said maneuver. These variables were selected after a prior survey, which took place in some Algerian ports.

The axes are communication, training, individual characteristics and the profile of stakeholders in the maneuver; regulatory and risk management aspects; meteorological factors that influence the

*Corresponding author: Bouzaher Abdelhakim, Research Laboratory in the Maritime Transportation Security Setram, Maritim National Superior School, Bou Ismail, Algeria, Tel:+25-99179176; E-mail: hakimbouzaher@yahoo.fr

Received February 02, 2018; Accepted March 30, 2018; Published April 08, 2018

Citation: Abdelhakim B, Manoubia M (2018) Appreciation of Stakeholders in Port Maneuver Regarding the Origin of Risk and its Consequences: The Case of Algerian Ports. J Coast Zone Manag 21: 458. doi: 10.4172/2473-3350.1000458

Copyright: (c) 2018 Abdelhakim B, et al. This is an open-access article distributed under the terms of the Creative Commons Attribution License, which permits unrestricted use, distribution, and reproduction in any medium, provided the original author and source are credited. 


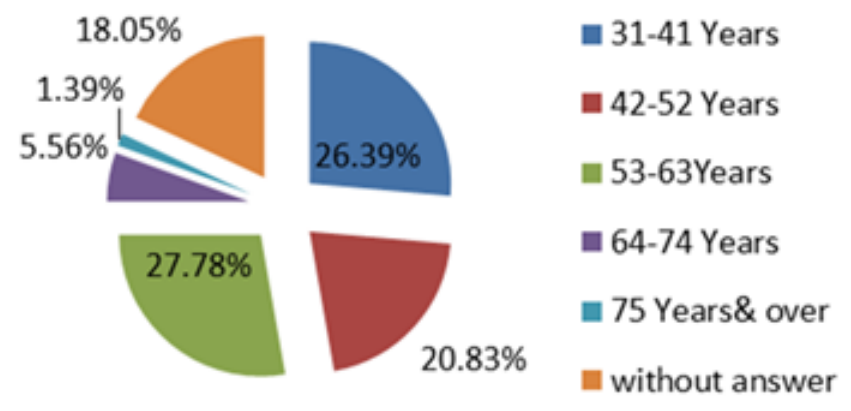

Figure 2: Age of stakeholders.

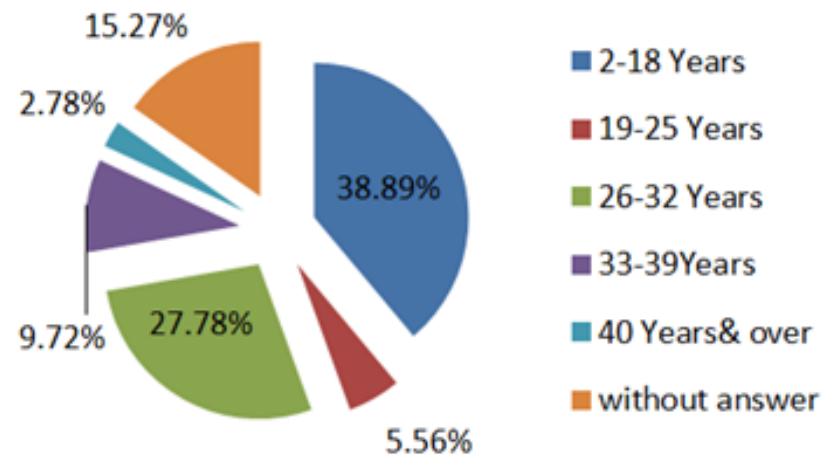

Figure 3: Experience of the stakeholders.

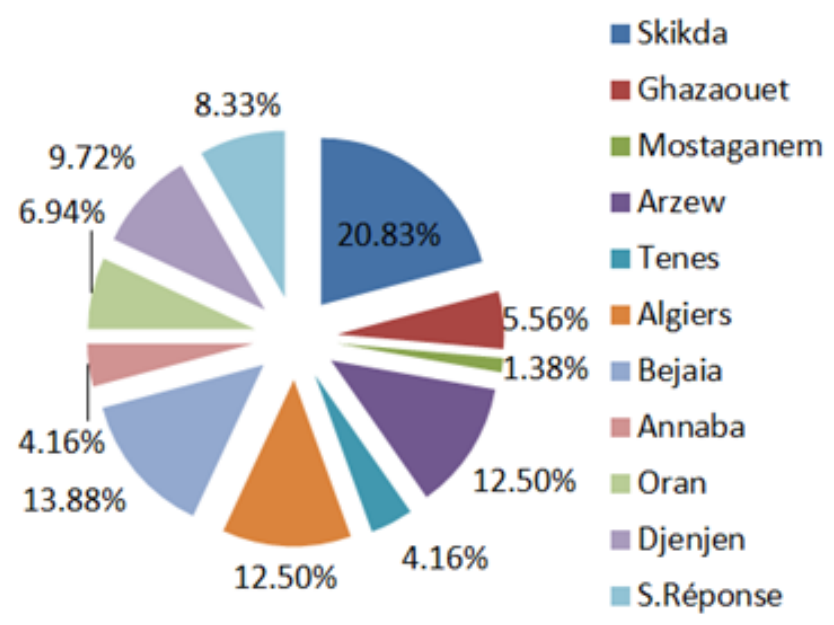

Figure 4: Homeport of the stakeholders. maneuver; the evaluation of security at the port and the consequence of risk [14-18]. The analysis of the data obtained statistically using descriptive statistics and the chi-squared (X2) test that allowed us to identify the significance of the differences recorded in stakeholders' answers.

\section{Results}

The results are presented according to the studied variables (axes of the questionnaire) and according to the characteristics of stakeholders who have participated in the study, namely: experience, age, port and function.

\section{Communication in port maneuver}

Two parameters regarding communication have been studied, the existence of communication difficulties and risk as a consequence of ineffective communication. The results obtained from communication difficulties during port maneuver regardless of the age of stakeholders confirm that the latter (especially between the ages of 31-63 years old) encounter difficulties (X2=22.86, $\mathrm{dl}=4, \alpha=0.01)$. These difficulties are encountered in all of the ports studied and to a lesser degree in the port of Mostaganem (X2=21.05, $\mathrm{dl}=9, \alpha=0.05)$.

All the subjects regardless of their functions with the exception of harbor masters recognize these communication difficulties $(\mathrm{X} 2=15,55$, $\mathrm{dl}=3, \alpha=0,05)$. As to the risk as a consequence of communication, it appears that regardless of the subjects' experience, the differences in their answers confirm that the risk is, according to stakeholders in port maneuver, a consequence of ineffective communication $(X 2=10.96$, $\mathrm{d} 1=4, \alpha=0.05)$.

Moreover, regardless of the port, the stakeholders assert that the risk is a consequence of ineffective communication $(\mathrm{X} 2=24,16, \mathrm{dl}=9$, $\alpha=0,01)$.

The results relative to the two characteristics of age and function are not statistically significant (age: $\mathrm{X} 2=7.52, \mathrm{dl}=4$, function: $\mathrm{X} 2=7.41$, $\mathrm{d} 1=3$ ). That being said, regardless of the age or function of the subjects, these factors do not influence the responses when considering the risk due to ineffective communication.

\section{Training and port maneuver}

Concerning training in the field of port maneuver regardless of the port, the differences in the subjects' responses are significant $(\mathrm{X} 2=27.27, \mathrm{dl}=9, \alpha=0.01)$. This means that training in the field of port maneuver is desired by the concerned parties regardless of the port. The rest of the characteristics of stakeholders, namely professional experience $(\mathrm{X} 2=3.63, \mathrm{dl}=4)$, age $(\mathrm{X} 2=5.96, \mathrm{dl}=4)$ as well as function $(\mathrm{X} 2=6.53, \mathrm{dl}=4)$ did not affect the subjects answers. This means that regardless of the experience of the subjects involved in the maneuvering and whatever their age and function, these variables are not related to the need for training in the field of maneuver.

\section{Individual characteristics and profiles of stakeholders in maneuver}

Half of the subjects questioned (36/72) consider that all the individual characteristics below are at the origin of the risk in port maneuver. They are namely age, occupational diseases, lack of concentration, lack of knowledge of the environment, the making of wrong decisions, the personality of stakeholders and the lack of speed.

In addition, ten subjects (10/72) give particular importance to the lack of concentration, the lack of knowledge of the environment, and 
making wrong decisions [19-21].

Moreover, there are other characteristics that have been identified such as overconfidence, (4/72) fatigue and stress (4/72), difficulty to communicate $(2 / 72)$ and the lack of anticipation $(2 / 72)$.

In addition to the individual characteristics, the recorded differences in the stakeholders' answers, regarding the necessity to possess a particular profile to exercise in port maneuver, were statistically significant.

Indeed, whatever the level of experience $(\mathrm{X} 2=11.66, \mathrm{dl}=4, \alpha=0.05)$, the age (X2=14.79, $\mathrm{d} 1=4, \alpha=0.05)$, homeport $\mathrm{X} 2=39.41, \mathrm{dl}=9, \alpha=0.01)$ or function $(\mathrm{X} 2=13, \mathrm{dl}=3, \alpha=0.01)$ of the subjects, the latter are in favor of the possession of a particular profile. However, not all of the subjects who participated in the study identified this profile. What appears the most is experience within the maritime field, which must be at least five years [5], and had proposals [22]. Maritime training also received proposals and was followed by knowledge of the port field with proposals $[6,9]$.

Concerning the knowledge outside of the maritime and port field [7], proposals have been made in the field of human relations and communication.

Concerning personality traits, self-control is essential for the job, which corresponds to proposals [10]. The latter is followed by the strength of personality (assurance and confidence) with proposals [7]. The cognitive (mental) aspect was directed towards the capacity to anticipate with proposals [4].

\section{Meteorological factors influencing the maneuver}

Meteorological factors in turn influence the proper performance of port maneuvering. This statement was confirmed in this study. It seems that (48/72) subjects consider that wind, current, bad visibility and swell are the most prominent meteorological factors in executing the maneuver. Also, the analysis of the responses demonstrates that the combination of these factors depends on the port. It appears, indeed, that the wind and current are determining factors in the port of DJENJEN, while in the port of Oran, wind and visibility seem to be the major influencers; wind, visibility and swell for the port of Algiers; whereas for the port of skikda and Arzew the decisive factors are rather wind, current and swell.

\section{Appreciation of regulatory aspects}

Whatever the characteristics of the subjects involved in the maneuver, it seems that the differences recorded in their responses are variable. They are significant when it comes to experience $(X 2=16,16$, $\mathrm{dl}=8, \alpha=0,05)$ and port $(\mathrm{X} 2=49,6, \mathrm{dl}=27, \alpha=0.01)$ and not significant when it comes to age $(\mathrm{X} 2=7.55, \mathrm{dl}=8)$ and function $(\mathrm{X} 2=8.31, \mathrm{dl}=6)$.

This means that stakeholders in maneuver consider that the national legislation and the international regulatory tools in the field of management of port security are fitting and this regardless of their experience and the port in which they practice. Age and function on the other hand cannot be tied to any regulatory aspect.

\section{Consequences of the risk}

Regarding the consequences of the risks arising from port maneuver, the differences recorded in stakeholders' responses are statistically significant for all the characteristics of these subjects, meaning professional experience, age, port and function of stakeholders.

The differences are significant depending on experience $(\mathrm{X} 2=31$, $\mathrm{dl}=4, \alpha=0.01)$, age $(\mathrm{X} 2=24.83, \mathrm{dl}=4, \alpha=0.01)$, port $(\mathrm{X} 2=23.08, \mathrm{dl}=9$, $\alpha=0.01)$ and function $(X 2=127, d 1=3, \alpha=0.01)$ of the stakeholders.

However, regardless of professional experience, age, homeport and function of stakeholders in port maneuver, they all confirm, in most cases, that the structures that are affected by the risk derived from port maneuver are the ship, the tugs and the harbor infrastructure.

\section{Port safety assessment}

Two parameters allowed us to study this axis: Assessing the management of port maneuver and assessing port safety.

Differences in stakeholders' responses to port maneuver management are statistically significant for all of the characteristics of the stakeholders.

Indeed, whether it be experience ( $\mathrm{X} 2=27.41, \mathrm{dl}=8, \alpha=0.01)$, age $(\mathrm{X} 2=45.29, \mathrm{~d} 1=12, \alpha=0.01)$, port $(\mathrm{X} 2=72.69, \mathrm{dl}=27, \alpha=0.01)$ or function of stakeholders $(\mathrm{X} 2=125.4, \mathrm{dl}=9, \alpha=0.01)$, the management of the maneuver in the port is considered to be under-developed.

The previous results did not affect the assessment of port safety by stakeholders in port maneuver. The differences recorded in the responses are statistically significant for all of the characteristics of stakeholders.

Indeed, the stakeholders in port maneuver consider port safety to be satisfactory and this regardless of their professional experience (X2=35.78, $\mathrm{dl}=12, \alpha=0.01)$, age $(\mathrm{X} 2=44.33, \mathrm{dl}=8, \alpha=0.01)$, port (X2=48.66, $\mathrm{d} 1=27, \alpha=0.01)$ or function $(\mathrm{X} 2=30.6, \mathrm{~d} 1=6, \alpha=0.01)$.

\section{Discussion}

The analysis revealed the existence of communication difficulties in port maneuvering, which corresponds to the results of the study carried out by UNCTAD in collaboration with the International Ports Association (IPA).

Indeed, ship docking operations were not systematically coordinated. Between the hours of planned, wanted and effective ship docking, there were at times shifts because of poor communication between stakeholders in the chain of operation. What is interesting in this work is that the port of Mostaganem is the only port where these difficulties are not reported. This could be explained by Mostaganem's port policy or simply by the fact that the number entry or exit maneuvers of ships is inferior to the number of maneuvers made in other ports. This will allow management of programming and communication between the various stakeholders during ship maneuver.

Communication difficulties are at the origin of the risk, as has been demonstrated by literature in this field. In addition, whatever the experience of the stakeholders in the maneuver and the port where the maneuver takes place, communication difficulties are at the origin of the risk. Such a result could lead port companies to consider ways to avoid an eventual risk by making communication more effective through a specific communication policy within the port environment. The difficulties encountered during the maneuvered stakeholders to suggest a training course in this field. Which is something that is not currently de rigueur, as the existing training course is a maritime training with prior experience in navigation. However, the concerned individuals, whatever the port in which they exercise, consider this insufficient. If it is a necessity, it will be necessary to reflect on the content of this training in order to distinguish it from what already exists and to make it more targeted and more specific to Algerian ports. It is in this state of mind 
that the National Maritime High School of Bou-Ismail has elaborated at the request of the Algerian Ministry of Publics Works and Transport a training program for aspiring pilots, comprising of several training components namely communication in ports, emergency management, security in port work, meteorological influence on port activity etc. Only, training needs must be more precise and better analyzed by port companies.

Regarding the individual characteristics of the stakeholders at the origin of risk in maneuver, it appears that there is a consensus in the proposals of the concerned individuals. Indeed, in addition to some personal characteristics, occupational diseases and age are questioned. The last result is quite interesting since more than half of the sample is over fifty years old. That said, even if stakeholders in the maneuver are not young, they are aware that it must be carried out by a younger population. This can be reasonable if we add to this parameter the occupational diseases that have proven in various studies their link with safety, such as the study conducted by the Ministry of the Environment, Energy and the French Sea in 2015 on accidents at work and maritime occupational diseases.

It also appears that experience in the maritime field ( 5 years at least), maritime training and knowledge of the port environment are essential to efficiently exercise the maneuver.

Outside of the maritime domain, mastery in human relations and communication is essential. In terms of personality traits, composure, self-confidence and self-control are desired characteristics in the job. In addition, anticipation is an indispensable aptitude in the maneuver.

Meteorological factors influence the execution of the maneuver in an efficient manner. Wind, current, bad visibility, and swell are the most important meteorological factors in performing the maneuver. The combination of these factors depends on the port. Indeed wind and current are determining in the port of Djenjen. Wind and visibility in Oran. However, in the port of Algiers, the dominant meteorological factors are wind, visibility and swell. Moreover, for the ports of Skikda and Arzew, wind, current and swell is the decisive factors.

These results (which remain to be confirmed) suggest that the meteorological factors involved in the execution of the maneuver are not necessarily the same in the different Algerian ports. So, even the execution of the maneuver can also be different from one port to another.

National legislation and international regulatory tools that are considered by stakeholders to be appropriate, regardless of their experience or the port in which they operate, govern port security management.

Therefore, we can deduce that the problem of port security is not a regulatory issue in Algeria. What need to be strengthened are the internal organizational plans of each port through effective risk management systems. We come back in this case, as is the case for the communication difficulties to the port company's policy in terms of risk management.

With respect to the consequences of hazards arising from port maneuver, stakeholders involved in maneuver (regardless of their experience, age, function and port) consider that the vessel, tugs and port infrastructure are the most affected by the risk. The last studied axis concerns the evaluation of safety through the maneuver management and safety assessment in port.

Regarding maneuver management, stakeholders in maneuver (whatever their experience, age, function and port) consider that the latter is less developed in Algeria.

This confirms the importance of stakeholder's perception. In addition, any proposal related to this management is to be discussed with the concerned parties, which is not currently done in Algeria. Furthermore, there is no question of imitating what is being done elsewhere as there is a need to design a specific policy for Algerian ports. It is also important to consider, as it was demonstrated by a study made by the Council of Canadian Academies on Accidents in Maritime Transport, the fact that the diversity of economic, social and cultural contexts still contributes to differences in risk profiles between regions.

This perception of maneuver management has not affected the assessment of port security made by stakeholders in port maneuver. Indeed stakeholders, whatever their characteristics, consider that safety in the port is rather satisfactory. This result can be considered positive, because even if there are communication difficulties and these difficulties are indeed at the origin of the risk in port maneuver, and even if there are some shortcomings in terms of regulation, those who are concerned by port maneuver consider that safety at the port is satisfactory. This evaluation, which is subjective, is in favor of decision makers who can think about improving port safety by counting on the support and contribution of the first concerned the stakeholders in the port maneuver.

\section{Conclusion}

The results of this study remain limited to Algerian ports and are much more related to port maneuver. It appears that the stakeholder involved in port maneuver, who is primarily the maritime pilot, can contribute and bring a plus to the risk policy adopted by the port company in particular and the maritime environment in general. Moreover, the question is not about establishing a maritime and port safety policy in Algerian ports, but rather about specifying this policy and going towards a risk profile depending on the region (port, meteorological characteristics, etc.). Still, it is not sufficient to rely on accident and incident data, and it will be necessary to identify the causes of risks at the level of maritime transport where the risk is greater. Furthermore, preventing risk remains everyone's business: government, international organizations, maritime and port affairs and industry. Thus, it is no longer enough to only talk about risk prevention policy at a port level.

\section{References}

1. Alesheikh AA, Ghorbanali A, Nouri N (2007) Coastline change detection using remote sensing. Int J Environ Sci Technol 4: 61-66.

2. Ayadi K, Boutiba M, Sabatier F, Guettouche MS (2015) Detection and analysis of historical variations in the shoreline, using digital aerial photos, satellite images and topographic surveys DGPS: Case of the Bejaia bay (East Algeria). Arab J Geosci 9: 1-18.

3. Bagheri $\mathrm{H}$, Khodabakhsh S, Gharib RM, Mohseni H (2006) Studying the coasta changes of Kiashahr-Dastak area from 1967 to 1993 using GIS. Science magazine of Bu Ali Sina University 2: 34-25.

4. Barnett V, Lewis T (1992) Outliers in Statistical Data. John Wiley \& Sons, New York.

5. Ben GI (2005) Outlier detection, Data mining and knowledge discovery handbook: A complete guide for practitioners and researchers. Kluwer Academic Publishers, The Netherlands.

6. Boak EH, Turner IL (2005) Shoreline definition and detection: a review. J Coast Res 21: 688-703.

7. Carter R (1988) Coastal environments: An introduction to the physical ecological and cultural systems of coastlines. Academic Press, US. 
Citation: Abdelhakim B, Manoubia M (2018) Appreciation of Stakeholders in Port Maneuver Regarding the Origin of Risk and its Consequences: The Case of Algerian Ports. J Coast Zone Manag 21: 458. doi: 10.4172/2473-3350.1000458

Page 5 of 5

8. Chen LC, Rau JY (1998) Detection of shoreline changes for tideland areas using multi -temporal satellite images. Int J Remote Sens 19: 3383-3397.

9. Comanicu D, Meer P (2002) Mean shift: A robust approach toward feature space analysis. IEEE Trans Pattern Anal Machine Intel 24: 603-619.

10. Cracknell AP (1999) Remote sensing techniques in estuaries and coastal zones an update. Int J Remote Sens 19: 485-496.

11. Crowell M, Leatherman SP, Buckley MK (1991) Historical shoreline change: error analysis and mapping accuracy. J Coast Res 7: 839-852.

12. Ford M (2013) Shoreline changes interpreted from multi-temporal aerial photographs and high resolution satellite images: Wotje Atoll, Marshall Islands. Remote Sensing of Environment 135: 130-140.

13. Gens R (2010) Remote sensing of coastlines: detection, extraction and monitoring. Int J Rem Sens 31: 1819-1836.

14. Hawkins D (1980) Identification of Outliers. Chapman and Hall, London.

15. Hodge V, Austin J (2004) A survey of outlier detection methodologies. Artificial Intelligence Review 22: 85-126.

16. Iglewicz B, Hoaglin D (1993) How to detect and handle outliers. ASQC Quality Press.
17. Lorestani G (2015) Forecasting annual changes of the Caspian Sea coastline (Gorgan-Rud river delta area), physical geography research 47: 254-241.

18. Kakroodi AA, Kroonenberg SB, Goorabi A, Yamani M (2014) Shoreline response to rapid 20th century sea-level change along the Iranian Caspian coast. J Coast Res 30: 1243-1250.

19. Kankara RS, Selvan CS, Rajan B, Arockiaraj S (2014) An adaptive approach to monitor the Shoreline changes in ICZM framework: A case study of Chennai coast. Ind J Mar Sci 43: 1271-1279.

20. Kannan R, Kanungo A, Murthy MVR (2016) Detection of shoreline changes Visakhapatnam Coast, Andhra Pradesh from multi-temporal satellite images. J Remote Sensing \& GIS 5: 1-8.

21. Kermani S, Boutiba M, Guendouz M, Guettouche MS, Khelfani D, et al. (2016) Detection and analysis of shoreline changes using geospatial tools and automatic computation: Case of jijelian sandy coast (East Algeria). Ocean \& Coast Manag 132: 46-58.

22. Kumar A, Narayana AC, Jayappa KS (2010) Shoreline change sand morphology of spits along southern Karnataka, west coast of India: a remote sensing and statistics based approach. Geomorphology 120: 133-152. 